\title{
A APLICABILIDADE DO LASER DE BAIXA POTÊNCIA NA REDUÇÃO DA SIALORREIA
}

\author{
Felipe Leonardo Rigo \\ Hospital Infantil João Paulo II. Fundação Hospitalar do Estado de Minas Gerais/FHEMIG \\ felipeleonardorigo@hotmail.com \\ Gabriela de Moura Magalhães Josephson \\ Hospital Infantil João Paulo II. Fundação Hospitalar do Estado de Minas Gerais/FHEMIG \\ gabidemoura@gmail.com
}

\begin{abstract}
RESUMO
INTRODUÇÃO: A terapia com laser de baixa intensidade possui uma excelente ação analgésica, anti-inflamatória e cicatrizante. Algumas patologias podem elevar a produção de saliva e o tratamento pode ser medicamentoso e cirúrgico. O laser de baixa potência é utilizado na prática clínica com bons resultados para inibição ou redução da sialorreia, porém, necessita de maior investigação. OBJETIVO: Relatar os resultados obtidos pela aplicação do laser de baixa potência em dois pacientes pediátricos internados em um hospital infantil do estado de Minas Gerais no ano de 202I. Estudo aprovado pelo Parecer: 4.886.533. DESCRIÇÃO DO CASO I: E.A.M.C, sexo feminino, 2 anos, diagnóstico de paralisia cerebral e microcefalia. I7/03/2I - Admitida no serviço de pronto atendimento com taquidispneia grave e febril, medicada, evoluiu com piora do padrão respiratório e encaminhada ao Centro de Terapia Intensiva Pediátrica. 22/03/2I - Evoluiu com piora da sialorreia e iniciado a aplicação do laser com o aparelho Laser Duo (MMO), potência de $100 \mathrm{~mW}$ e comprimento de onda de $808 \mathrm{~nm}$. Aplicado nas glândulas submandibulares, utilizando 36J de energia de cada lado em um único ponto de aplicação. As sessões ocorreram por 5 dias consecutivos, intervalo de 2 dias e por mais 3 dias seguidos. Observado redução significativa da sialorreia. No dia 05/04/2I- Paciente sem sialorreia DESCRIÇÃO DO CASO 2: L.G.V.M, sexo masculino, IO anos e 9 meses, diagnóstico médico ao nascimento de paralisia cerebral por toxoplasmose congênita, paciente possui traqueostomia e gastrostomia. No dia 04/05/2I é admitido na unidade de cuidados paliativos da instituição devido a traqueíte refratária. Durante internação foi observado sialorreia importante. Foram realizadas sessões de Laserterapia, com potência de $100 \mathrm{~mW}$. O comprimento de onda utilizado foi $808 \mathrm{~nm}$. Foi aplicado uma energia de 45J em um único ponto em cada glândula submandibular, gastando um total de 7 minutos e 30 segundos de cada lado. As aplicações ocorreram de segunda-feira a sexta-feira, por duas semanas consecutivas. Houve redução significativa da sialorreia no paciente após as sessões com laser de baixa potência CONCLUSÃO: Foi observado eficácia na utilização do laser de baixa potência em ambos pacientes. É imperativo novos estudos que comprovem os seus benefícios pelo baixo custo, não ser invasivo e fácil manejo.
\end{abstract}

PALAVRAS-CHAVE: Lasers; Eliminação salivar; Pediatria 